\title{
In Defense of the Agent and Patient Distinction: The Case from Molecular Biology and Chemistry
}

Philosophers, tracing back to Aristotle, traditionally distinguished between agents and patients in causal interactions. Agents interact with patients and patients suffer change as a result. Recently, many philosophers have challenged the agent/patient distinction, arguing instead that causal interactions are symmetrical, consisting in mutually interacting entities. Hence, they also argue that there is no principled basis for the agent/patient distinction.

In this paper, I defend the distinction. I do so by arguing that there is a widespread type of causal interaction between distinct entities where an asymmetry results due to the interaction, providing principled grounds for the agent/patient distinction. The type of interaction is when one of the two (or more) interacting entities undergoes a change in its kind membership, structure, causal powers, or intrinsic properties as a result of the interaction, while the other does not. There are many examples of this type of interaction in molecular biology and chemistry. I focus specifically on (i) the actions of enzymes on substrates and (ii) $\mathrm{H}_{2} \mathrm{O}$ molecules breaking polarized molecules' bonds.

After giving a brief overview of previous and historically important accounts of the agent/patient distinction, I present the critics' arguments. I then turn to the positive case, arguing that there are many interactions resulting in an asymmetry that provides a principled basis for distinguishing agents from patients. Finally, I lay out and to a limited extent defend several commitments of my account and respond to objections.

\section{Part 1 Agent and Patient Distinction Overview}

I'll start with an initial characterization of previous accounts of the agent/patient distinction before turning to criticisms of it in Part 2. I'll then defend a nuanced version of the distinction in 
Parts 3 and 4. I note that the account I defend, while informed by earlier accounts, ultimately follows the spirit rather than the precise letter of the accounts I briefly present in Part 2. ${ }^{1}$

I'll start by presenting criteria for some entity to be a patient in a causal interaction. Take a sculptor molding clay. In this interaction, clay is the patient for two reasons. First, the clay is what ultimately changes in the interaction. Second, the clay changes because of its interaction with another entity, the sculptor. The first reason is distinct from the second because there are entities that spontaneously change rather than changing because of their interactions with other entities. For example, in beta decay, a neutron spontaneously changes into a proton and emits an electron and a neutrino. While beta decay is a change, it isn't a change due to the neutron's interacting with another entity. So a key criterion of an entity being a patient is that it changes as a result of interacting with another entity. This has historically been phrased in several different ways: The patient receives a change or the patient suffers change.

The agent can be understood in light of the patient. The agent is the entity that interacts with the patient and as a result of the interaction, the patient changes. When sculpting clay, the sculptor is the agent, the entity that changes the clay by molding the clay. In this sense, the agent is what acts on the patient, while the patient - the clay-is what receives the change in shape.

Traditional accounts of the agent/patient distinction also distinguished between active and passive powers. As we shall see in the next section, most critics of the agent/patient distinction are powers realists. Yet they deny both the agent/patient and the active/passive power distinctions.

According to Aristotle, a power in general is a source of change. An active power is a source of change in something other than the thing changed (Metaphysics Book IX Ch 1,

\footnotetext{
${ }^{1}$ See, for example, Aristotle, Metaphysics Book IX Ch. 1 1045b28-1046a35 and Meterology Book IV Parts 4-9; Aquinas ST, 1a q25 a1c; and Locke, ECHU, 1.21.2 and 1.21.72.
} 
1045b28-1046a35). Specifically, the active power is the power exercised by the agent on the patient, when interacting with the patient (ibid). The active power is the feature of the agent that accounts for why it is able to produce a change in a patient (ibid). A passive power is a feature of the patient that accounts for why the patient is able to be changed in the way it is changed by the agent. Hot and wet clay can be molded but not shattered by a sculptor. Hardened clay can be shattered but not molded. Aristotle gives numerous examples of passive powers in his Meteorology, including: ${ }^{2}$ meltability ${ }^{3}$, hardenability ${ }^{4}$, thickenability ${ }^{5}$, solubility ${ }^{6}$, combustability ${ }^{7}$, impressionability $^{8}$, and malleability. ${ }^{9}$

Later figures such as Aquinas and Locke agreed with the broad contours of Aristotle's characterization of agent/patient and active/passive power distinctions. According to Aquinas, an active power "is the principle of acting upon something else" while a passive power "is the principle of being acted upon by something else" (ST 1a q25 a1c). Locke as well argued that “[p]ower, thus considered, is two-fold, viz. as able to make, or able to receive, any change: the one may be called active, and the other passive power" (ECHU 1.21.2). The passive power, according to Locke, is the capacity to receive an impression from an external agent (ECHU 1.21.72), which is tantamount to claiming that the passive power accounts for the patient's ability to be changed by or acted on by an external agent. ${ }^{10}$

To summarize this brief survey of others' accounts of the agent/patient and active/passive

\footnotetext{
${ }^{2}$ According to Aristotle, the passive powers of bodies account in part for their nature and kind membership, differentiating them from one another. See Metereology Book IV, Ch. 8, 385a1-20.

${ }^{3}$ Ibid Ch. 4, 381b26-28.

${ }^{4}$ Ibid Ch. 6, 382b28-383b17.

${ }^{5}$ Ibid Ch. 7, 383b19-384a2.

${ }^{6}$ Ibid Ch. 7, 384a34-384b14.

${ }^{7}$ Ibid Ch. 7, 384b15-16.

${ }^{8}$ Ibid Ch. 9, 386a18-29.

${ }^{9}$ Ibid Ch. 9, 386b18-26.

${ }^{10}$ See also R.M. Harre (1970:87) and E.J. Lowe (2013: 159).
} 
power distinctions, I draw attention to two important similarities between active and passive powers. First, both kinds of powers are sources of change. Both a metal wire's bendability (a property a bowling ball lacks) and a human's ability to bend a wire are sources of the change that the wire undergoes when bent. Second, both kinds of powers can exist without being manifested. A wire is bendable even when not bent and a human can bend a wire even when not bending.

Nonetheless, there are differences between the two types of powers, which point to important differences between agents and patients. An agent is the entity producing a change in a distinct entity in a causal interaction. The patient is the entity that changes when interacting with the agent. An active power is a power of an agent to produce the change in a patient. A passive power is the property of the patient that accounts for why it changes in the specific way it changes when interacting with the agent. When the human bends the wire, the human is the agent and the wire is the patient. The wire is what is changed: At the end of the interaction, the wire has a different shape, a shape that the wire by itself doesn't have the ability to change. The human's power to bend the wire is an active power while the wire's bendability is a passive power. A weak human wouldn't have the power to bend the wire. A concrete pipe doesn't have the passive power to be bent by a human. ${ }^{11}$

\section{Part 2 The Rejection of the Agent/Patient Distinction}

Recently, many philosophers have explicitly rejected the agent/patient and active/passive power distinctions. For example, C.B. Martin has argued that the "power to give versus the power to receive," "agent versus patient," and "active versus passive" distinctions are all "unhelpful

\footnotetext{
${ }^{11}$ I note that Aristotle, Aquinas, and Locke took activity and passivity to be intrinsic features of powers. In the account I defend in Parts 3 and 4, activity and passivity are objective roles that powers play.
} 
distinctions" (1993: 182). R.D. Ingthorsson similarly argues that causal production doesn't consist in "an action of an 'agent' upon a 'patient"' (2003: 4). Any asymmetry alleged in a causal interaction, such as the asymmetry between agents and patients, is "purely subjective" (2003: 1819). John Heil argues that the agent/patient and active/passive power distinctions are an inappropriate "byproduct of our explanatory practices and contingencies of experimental manipulation" (2012: 74). Tobias Hannson-Wahlberg argues that a distinction between active and passive powers is "unnecessary and hence uneconomical" (2019: 1606). Stephen Mumford and Rani Lill Anjum also argue that there is "no solid reason why we should privilege one of these two partners and depict it as the active partner" (2018: 269). Nor can they find a good reason for "relegating the other partner to a passive supporting role" (Ibid). Furthermore, there is no principled basis to say that one entity "plays the active role with the other passive" (2018: 269).

Before looking at their critiques of the agent/patient and active/passive power distinctions, it's important to note that there are number of similarities between these philosophers views on causation and powers and those who affirm the distinctions. Both agree that powers are irreducible to other entities, such as categorical properties. Both agree that powers can exist unmanifested. So, to see why they reject the distinctions, it's crucial to see how they understand the role of powers in causation. According to the distinction's critics, causation consists in "constellations" or "power nets" of reciprocal, symmetrical, mutually manifesting partner powers.

To clarify what is meant, take the attraction between a proton and an electron, such as in a hydrogen atom. A proton and electron are attracted to each other because of the proton's positive charge and the electron's negative charge. The charges are the partner powers in this 
interaction. Neither the proton's positive charge nor the electron's negative charge is alone adequate for the attraction between the two particles. Instead, both powers are required. Given that the proton and electron are attracted to each other because of their opposite charges, the two particles interact. The proton doesn't simply act on the electron as agent to patient, as if the proton pulls the electron to it, for the electron pulls the proton as well. Both pull each other together. The proton's and electron's attraction to each other is the mutual manifestation of their positive and negative charges, respectively. The attraction is further reciprocal and symmetrical. The proton attracts the electron and the electron attracts the proton. To the extent that the proton attracts the electron, the electron attracts the proton.

In this example, there is no principled basis to single out one of the two entities as agent and the other as patient. There is also no principled basis to single out one power (e.g., the positive charge) as active and the other power (e.g., the negative charge) as passive. Instead, both entities act on each other and they do so because of their charges.

Critics of the agent/patient and active/passive power distinctions claim that these sorts of situations, where there is no principled basis to single out an entity as an agent or a patient, are not rare. Instead, according to Heil, "they are by far the most common species of causal interaction" (Heil 2012: 119). As Ingthorsson points out, this isn't a new idea nor is it distinctive to recent causal powers realists. It is found, for example, in classical mechanics, where "interactions between material bodies are reciprocal" and "with respect to forces quantitatively equal" (Ingthorsson 2002: 5). ${ }^{12}$ This extends to examples beyond the attraction of bodies due to their opposite charges or the gravitational pull of their masses. Even salt's being dissolved in

\footnotetext{
${ }^{12}$ Ingthorsson appeals to Newton's third law, which states that the forces between two interacting bodies are quantitatively equal (even though opposite in direction). See Ingthorsson (2002: 12). See also Bunge (1959/2009: 170-171).
} 
water, according to Heil, "is the outcome of a causal process, a causing, that is itself symmetrical" (Heil 2012: 119). In all these examples, there is a reciprocal interaction of mutually manifesting partner powers. ${ }^{13}$ In Parts 3 and 4, I challenge the contention that there are no principled reasons to distinguish agents from patients, in part by pointing to several examples of other types of widespread causal interactions.

\subsection{What's at Stake?}

If critics of the agent/patient distinction are right, then there are no principled ontological grounds for the distinction. That is, in causal interactions, there isn't any sort of ontological asymmetry that indicates a genuine distinction between agents and patients.

Before turning to my defense, it's important to address what's at stake. First, the agent/patient distinction underlies much of our language. Predicates such as "bendable" or "malleable" are assumed to be predicated of entities that suffer change when interacting with other entities with certain properties. A theory of causation that denies that there are principled grounds for the distinction then incurs a cost. For if there are principled reasons for the agent/patient distinction, then there's an explanation for why language is rife with the distinction, both in grammar (e.g., active and passive voice) as well as the meanings of terms like "bendable" and "malleable".

I note that I am not arguing that there being principled grounds for the agent/patient distinction is necessary for explaining why the distinction is laden throughout language. I also do not claim that human language carves reality at the joints or that ontology can always be read off the surface features of language. Instead, I argue that a metaphysics which posits the distinction has an advantage over one which denies it, as the metaphysics that posits the

\footnotetext{
${ }^{13}$ Martin distinguishes reciprocity from symmetry and denies that symmetry is required for reciprocity. See Martin (1993: 185).
} 
distinction can better explain why the distinction is laden throughout language.

Additionally, as Anna Marmodoro has argued, the distinction can ground the direction of causation and do so in a way that is consistent with cases of simultaneous causation, an advantage lacking in theories of causation that ground the direction of causation on the direction of time. ${ }^{14}$ I note that in this paper, my primary aim is not to defend the direction of causation. Instead, I aim to defend the thesis that there are principled grounds for the distinction in a widespread type of interaction. Yet this distinction can further defend causation's direction.

Lastly, as I address in greater depth soon, the agent/patient distinction underlies some crucial concepts in chemistry and biology, such as chemical catalysis. I turn now to this point.

\section{Part 3 A Principled Way to Distinguish Agents from Patients}

In what follows, I argue that there are principled ontological grounds for the agent/patient distinction in a widespread type of interaction. As discussed in Part 2, critics of the distinction base their case on the symmetries found in the interactions between subatomic particles or expressed by classical mechanical laws. However, when one looks at many interactions in molecular biology and chemistry, there is an asymmetry that provide grounds for the distinction in a way that satisfy the broad contours of earlier accounts of it, as I shall argue.

The type of interaction where I argue that there is a principled basis to distinguish agents from patients can be characterized thus: An entity is a patient in an interaction when the entity suffers a change in its kind, structure, causal powers, or intrinsic properties, as a result of the interaction. An entity is the agent in the same interaction when it does not suffer a change in its kind, structure, causal powers, or intrinsic properties, at the end of the interaction. Instead, the

\footnotetext{
${ }^{14}$ Marmodoro has defended this point in several publications. See Marmodoro (2014) and (2017).
} 
agent entity at the end of the interaction persists in its kind, structure, causal powers, or intrinsic properties. Importantly, as I shall show, interactions of this type are widespread in chemistry and molecular biology.

Before turning to examples, it's crucial that I clarify several points about the account of the distinction I defend. First, in this paper, I am presenting a sufficient condition for the agent/patient distinction, rather than necessary and sufficient conditions. My account is consistent with there being other types of interactions where there are principled reasons to distinguish agents from patients, such as interactions where both entities undergo a change in kind, structure, powers, or intrinsic properties, but they change in different respects. ${ }^{15}$ Examples include oxidation/reduction reactions and acid/base neutralization reactions. In this paper, however, I'll focus on the account I've canvassed above where one entity persists in kind, structure, powers, or intrinsic properties while the other does not.

Second, according to what I argue is a sufficient condition for the distinction, agency and patiency are roles that entities take on, depending on the other entities interacted with. ${ }^{16}$ An entity that is an agent in one type of interaction may be a patient in a different type of interaction. Likewise, powers play either active or passive roles, depending on the type of interaction. In some interactions, a power may be responsible for a change in a distinct entity other than the power's bearer. In other interactions, the same power is responsible for a change in its own bearer. This is both consistent with and influenced by earlier accounts. For example, according to Locke, a passive power is what makes its bearer "able to receive" a change or "receive an impression" from a distinct entity. The passive power then is what accounts for why an entity is changed when interacting with a distinct entity. That same power might play an active role in an

\footnotetext{
${ }^{15}$ See Marmodoro (2017: 72-73) and (2020: 63).

${ }^{16}$ Marmodoro similarly argues that activity and passivity are roles. See, for example, (2017: 74).
} 
interaction with a different kind of entity. ${ }^{17}$

However, while agency and patiency are roles rather than intrinsic features of entities, they are nonetheless objective roles that the entities play and which are grounded in part in their intrinsic features, such as their powers, as well as the intrinsic properties of the entity interacted with. So while agency and patiency are roles, it does not follow that the distinction is unprincipled or subjective. It isn't subjective that an entity suffers change as a result of an interaction with a distinct entity while the other entity doesn't change. This is consistent with Aristotle's and Aquinas's accounts, who held that there are no pure agents or patients, except in limit cases such as God, the unmoved mover, and prime matter. ${ }^{18}$ I respond to this objection in greater depth in Part 4.

Finally, I note that my account is indebted to Marmodoro's and should be considered as an expansion upon and further development of her account. ${ }^{19}$ My paper builds on Marmodoro's work in several respects. First, in Part 4.3, I respond in greater depth to an objection that given that agency and patiency are roles, a view of both Marmodoro's account and mine, the distinction is subjective. Second, in Part 4.4, I respond to a related objection that given that agency and patiency are roles, the distinction adds nothing to ontology. Third, in Part 4.1, I respond to an objection from reductionists that threatens a key example of both Marmodoro's account and mine - water's dissolving salt, by defending in some detail that $\mathrm{H}_{2} \mathrm{O}$ and $\mathrm{NaCl}$ molecules are strongly emergent entities with emergent powers. Fourth, in Part 4, I also clarify and to a limited extent defend some another commitment of our accounts - realism about chemical and molecular kinds. Fifth, I develop a significant portion of my account by drawing

\footnotetext{
${ }^{17}$ Although my account is consistent with some purely passive powers, I won't argue for their existence in this paper.

18 See, for example, Aristotle, Physics, 202a5-7. See also Marmodoro (2014:41) and Harre and Madden (1975: 89).

${ }^{19}$ See Marmodoro (2014), (2017), and (2020).
} 
on an example of a widespread interaction from molecular biology that has until now not been considered in the debate on the agent/patient distinction by Marmodoro or others but which could help "tip the scales" in favor of the distinction - enzyme catalysis.

\subsection{Enzymes as Catalysts}

There are widespread examples of interactions that satisfy conditions that I argue are sufficient for some entity to be an agent, in that they do not change in their kind, structure, powers, or intrinsic properties while the entities they interact with in certain types of interactions do change and hence are patients. I start with an example that has until now not been considered by philosophers in discussions about the agent/patient discussion, nor in the broader literature on causation and causal powers. Specifically, I want to draw attention to entities that behave as catalysts in chemical and biochemical reactions. Catalysts are entities that change the speeds of chemical reactions without themselves being consumed by or undergoing any permanent chemical change in the process (Alberts G:6; Brown G:2). Furthermore, catalysts are very common and are key to many biological, atmospheric, and oceanic reactions (Brown 605). In this paper, I focus primarily on the actions of enzymes (biochemical catalysts) on substrates. In these interactions, enzymes play the agent role and substrates play the patient role: The substrate undergoes a kind-change, while the enzyme persists. The example of enzymes also introduces a new kind of support for the agent/patient distinction not available to other frequently discussed examples (e.g, water-solubility): In Part 4.2.1, I provide evidence that the naturalistic biological function of enzymes is to behave as agents when interacting with substrates.

As catalysts, enzymes speed up chemical reactions without being consumed by the reaction (Reece et al 2011: 83). Enzymes do so by contorting substrate molecules into highly unstable states. This results in either broken bonds (in anabolic reactions where one substrate is 
broken into two products) or a newly formed bond (in catabolic reactions where two substrata are combined into one product) (Reece et al 2011: 84). I'll focus on anabolic reactions.

While many reactions where one reactant is broken up into two products could happen spontaneously, the rate they occur without a catalyst is too slow for a cell's survival and other crucial biological processes. ${ }^{20}$ With enzymes, however, crucial reactions occur at much higher rates, ensuring a cell's survival. For example, sucrose (table sugar) in water can spontaneously hydrolyze, resulting in the products glucose and sucrose, but the process takes years. If the enzyme sucrase is added to water, however, the sucrose hydrolyzes in mere seconds.

How then do enzymes speed up the necessary reactions for cellular processes? The answer lies in their shape and charge-distributions. Enzymes are complex macromolecules, usually proteins, with a unique three-dimensional shape. The specific shape determines what reactants or substrates the enzyme can act on. The enzyme does so through its active site, a groove on the enzyme's surface that fits only some substrate molecules (Reece et al 2011: 84).

The enzyme's active site starts out empty, which the substrate attaches to via weak chemical bonds. Once attached, the enzyme's active site changes shape slightly, fitting the substrate more tightly, in an induced fit. The induced fit contorts the substrate's bonds, straining them so that they are easily broken. The result is the substrate is broken into the products of the reaction, such as glucose and fructose resulting from sucrase acting on sucrose (Reece et al 2011: 84).

What's key is that the enzyme persists through the reaction, returning to its initial state. While the enzyme undergoes some conformational changes during the interaction, it returns to its

\footnotetext{
${ }^{20}$ Given the amount of energy needed, the processes would be too slow for survival, as a great deal of energy needs to be absorbed to weaken the reactant molecules' bonds enough to break (Reece et al 2011: 83). While adding heat could speed up the reactions without requiring enzymes, the quantities of heat needed for the activation energy kill the cell. (Ibid; Alberts 73).
} 
initial state at the end of the process. This is analogous to someone crushing a soda can by clenching their fists. The enzyme retains the same shape, powers, and kind membership, allowing it to act on another substrate. ${ }^{21}$ The products of the interaction, however, are vastly different in kind, shape, mass, charges, and powers than the substrate. That is, the substrate does not persist.

So when enzymes and substrates interact, there is an ontological asymmetry: The enzymes persist while the substrates do not. ${ }^{22}$ The substrates suffer a kind-change from their interaction with enzymes. Hence, in these interactions, enzymes are agents while substrates are patients.

As stated above, agent and patient are roles such entities play in certain types of interactions. Enzymes can play the patient role in other interactions. For example, temperature and $\mathrm{pH}$ can permanently alter an enzyme's shape (Reece et al 2011: 84). A noncompetitive inhibitor can bind to an allosteric site on the enzyme (a different place than the active site) and alter the enzyme's shape so that it cannot act on substrates (Reece et al 2011: 85). Yet it's worth repeating that traditional accounts of the agent/patient distinction also held that agents can be patients, except in limit cases, such as God or the unmoved mover.

Furthermore, the enzyme's and substrate's shape and charge-distribution play the active and passive power roles, respectively. When interacting with the enzyme, the substrate's shape and charge-distribution accounts for why it suffers a kind-change and the enzyme's shape and

\footnotetext{
${ }^{21}$ As Daniel Nicholson notes, while recent advances in molecular biology show that some cellular functions are carried out by proteins that lack a stable structure and change when binding to targets, enzyme catalysis requires that enzymes have a clearly-defined three-dimensional structure (Nicholson 2019: 114).

${ }^{22}$ In this section, I use the biochemical rather than Aristotelian meaning of the terms "substratum" and "substrata" when discussing enzyme catalysis. The substratum is the entity converted into chemical products by the enzyme (in anabolic reactions). Of course, the two meanings are similar, as the Aristotelian meaning likely influenced the biochemical meaning.
} 
charge-distribution accounts for why it changes the substrate. In other cases, the substrate's shape and charge-distribution may play an active power role.

\subsection{Water Solubility}

The other example of this type of interaction I consider is from chemistry: water dissolving salt. I present this example because it is used as a frequent example of the agent/patient distinction but also is used in arguments against the distinction. Lowe (2013:159), for example, has argued that when water dissolves salt, water is the agent and salt is the patient. Yet according to Heil, a critic of the distinction, when water dissolves salt:

"[T]his interaction is, or appears to be, continuous, not sequential; it is, or appears to be, symmetrical. Both the salt and the water work in concert to yield a certain result: the salt's being dissolved in water" (2012: 118-19).

Furthermore, Heil argues that "salt and water possess reciprocal powers or dispositions. The salt's dissolving is a mutual manifestation of these dispositions" (2012: 118-19). Hence, Heil rejects the view that water is the agent and salt the patient or vice versa. Mumford and Anjum likewise argue:

There seems to be no solid reason why we should privilege one of these two partners and depict it as the active partner - the trigger or stimulus - while relegating the other partner to a passive supporting role. There seems to be no ontologically serious difference between the positions of the sugar and the liquid." (2018: 269)

However, as Marmodoro has pointed out, when one looks closer- specifically at the molecular rather than macroscopic level, there are indeed principled reasons to hold that individual $\mathrm{H}_{2} 0$ molecules are agents while sodium chloride molecules $(\mathrm{NaCl})$ are patients. Marmodoro writes, "In the causal interaction of water and salt, polarized water molecules break the bond between the negative chloride ions and the positive sodium ions; whereas salt does not break the water molecules" (2017:73).

In what follows, I describe water's dissolving salt with far greater detail than has been 
given before when used as an example of the agent/patient distinction and when the distinction's critics target it. Water's power as a solvent is a frequent example in discussions of the distinction, so it's worth pursuing an in depth look at the chemical details. As I'll show, a detailed examination of water dissolving salt at the molecular and chemical level satisfies the sufficient condition for the agent/patient condition defended in this paper. I also return to the example of water dissolving salt in section 4.1, where I look at even more chemical and molecular features of it, when responding to a reductionist objection.

At the molecular level, $\mathrm{H}_{2} \mathrm{O}$ molecules break the bonds of $\mathrm{NaCl}$ molecules, splitting $\mathrm{NaCl}$ molecules into $\mathrm{Na}^{+}$and $\mathrm{Cl}^{-}$ions while $\mathrm{H}_{2} \mathrm{O}$ molecules remain intact (Brown 2009: 529). $\mathrm{H}_{2} \mathrm{O}$ is a polar molecule, with the oxygen end having a slight negative charge due to oxygen's high electronegativity while the hydrogen ends have slight positive charges (Brown 2009: 354). The oxygen and hydrogen atoms are also covalently bonded to each other, the strongest type of chemical bond. $\mathrm{NaCl}$ (table salt) results from weaker ionic bonds between sodium and chlorine. A sodium atom gives its valence electron to a chlorine atom, so both atoms become stable, resulting in a positively charged sodium cation $\mathrm{Na}^{+}$and a negatively charged chlorine anion $\mathrm{Cl}^{-}$. In virtue of their opposite charges, the $\mathrm{Na}^{+}$and $\mathrm{Cl}^{-}$ionically bond to each other as a sodium chloride molecule (Brown 2009: 209-302).

When $\mathrm{H}_{2} \mathrm{O}$ molecules surround a $\mathrm{NaCl}$ molecule, the $\mathrm{H}_{2} \mathrm{O}$ molecules pull apart the $\mathrm{NaCl}$ 's bonds. Specifically, water molecule's negative oxygen end attracts the positive $\mathrm{Na}^{+}$while the water molecule's positive hydrogen end attracts the negative $\mathrm{Cl}^{-}$. Given that $\mathrm{NaCl}$ is formed by a weak ionic bond while $\mathrm{H}_{2} \mathrm{O}$ is formed by stronger covalent bonds, the $\mathrm{NaCl}$ separates into $\mathrm{Na}^{+}$and $\mathrm{Cl}^{-}$ions, which then move freely apart from each other (Brown 2009: 528-29).

So when $\mathrm{H}_{2} \mathrm{O}$ molecules interact with $\mathrm{NaCl}$ molecules, the $\mathrm{H}_{2} \mathrm{O}$ molecules remain intact. 
They do not change in kind; instead they persist. The $\mathrm{NaCl}$ molecules, however, do not persist. Instead, they change kind. In this respect, the interaction is asymmetrical. Therefore, I argue that when interacting, $\mathrm{H}_{2} \mathrm{O}$ molecules are agents while $\mathrm{NaCl}$ molecules are patients, on the criteria of the agent/patient distinction in this paper. Additionally, the polarity of the $\mathrm{H}_{2} \mathrm{O}$ molecule plays the active power role while the $\mathrm{NaCl}$ 's ionic bonds play the passive power role. The ionic bonds accounts for why $\mathrm{NaCl}$ suffers a kind change when interacting with $\mathrm{H}_{2} \mathrm{O}$.

\section{Part 4 Objections and Replies}

In this section, I respond to several objections to my account of the agent/patient distinction: a reducibility objection and several variants of an objection that the agent/patient distinction is subjective. In responding, I also make explicit assumptions that until this point were implicit: there are emergent entities and powers, there are chemical and molecular kinds, and there are biological functions. I note that I cannot give a full defense of these assumptions here. Nonetheless, the assumptions are plausible and are held by many philosophers, chemists, and biologists. Importantly, as I'll show, some critics of the agent/patient distinction also defend some of these assumptions. Regardless, my overall argument here is a conditional: Given my assumptions, there is a principled way to distinguish agents from patients in many interactions.

\subsection{Assumption: Emergent Entities and Powers}

The first assumption is that there are emergent entities with emergent powers. Specifically, I assume that molecules such as $\mathrm{H}_{2} \mathrm{O}$ and macromolecules such as enzymes are emergent entities with novel causal powers that are not reducible to their constituent atomic or subatomic particles'

powers. I present this assumption because some critics of the agent/patient distinction also favor reductive ontologies, such as Heil (2012). A reductionist objection can be expressed thus: 
Interactions between atoms, molecules, and macromolecules are reducible to interactions between subatomic particles. Yet interactions between subatomic particles are symmetrical. E.g., when two electrons repel each other, there is no reason to favor one as the agent and the other as the patient. The repulsion is mutual. Given that interactions between subatomic particles are symmetrical and interactions between higher level entities such as molecules are reducible to interactions between subatomic particles, interactions between higher level entities are ultimately symmetrical as well. There may be pragmatic reasons, but no ontological reasons to label one entity as agent and the other as patient.

Furthermore, in response to my argument that when one entity suffers a change in kind, structure, powers, or intrinsic properties, while the other does not, the former is a patient and the latter is an agent, the reductionist may argue:

In the examples of higher-level entities (e.g., water molecules) used to argue for a principled agent/patient distinction, while the alleged higher-level entities do not persist, their lower-level subatomic constituents do persist. As higher-level entities and the interactions between such entities are reducible to subatomic particles and their symmetrical interactions, there are no principled ontological reasons to label some subatomic entities as agents and others as patients.

In response, I note first that I will not challenge the inference that if the interactions between higher-level molecules are reducible to interactions between subatomic particles, then there are no principled ontological reasons to distinguish agents from patients in these interactions.

However, there are reasons to dispute the reducibility of molecules to subatomic particles as well as the interactions between molecules to interactions between subatomic particles. I note that I cannot offer a full defense of their irreducibility in this paper. Others have already done so (see, for instance, Bogaard 1978, Scerri 1997, and Hendry 2017). ${ }^{23}$

Nonetheless, there are plausible reasons to hold that the higher level entities' powers in at least one of my examples are not reducible to their subatomic constituents' powers. I'll focus

\footnotetext{
${ }^{23}$ For example, Hendry (2017: 153-4) notes that molecular kinds such as ethanol and dimethyul ether have the same Schrodinger equation but nonetheless different properties. Ethanol and dimethyul are isomers - molecules having the same atomic constituents but different shapes. The differing shapes result in different levels of solubility and boiling points.
} 
specifically on $\mathrm{H}_{2} \mathrm{O}$ molecules' powers. $\mathrm{H}_{2} \mathrm{O}$ molecules can break $\mathrm{NaCl}$ into $\mathrm{Na}^{+}$and $\mathrm{Cl}^{-}$because $\mathrm{H}_{2} \mathrm{O}$ molecules can form hydrogen bonds. ${ }^{24}$ It's especially worth focusing on this example, as water dissolving salt is a frequent example of the agent/patient distinction and a frequent target of the distinction's critics. ${ }^{25}$ Additionally, as others argue, there is a plausible case that the power to form hydrogen bonds is an emergent power. ${ }^{26}$

A water molecule's charge, like its atomic constituents, is electrically neutral. However, due to the oxygen atom's higher electronegativity, a water molecules atomic constituents' covalent bonds are polar. The polar covalent bond is responsible for the water molecule's distinctive shape and uneven charge distribution. So while an $\mathrm{H}_{2} \mathrm{O}$ molecule as a whole is electrically neutral, the oxygen end is partially negative while the hydrogen ends are partially positive.

Due to the shape and uneven charge - properties of the whole molecule rather than its atomic or subatomic constituents - the water molecule can form the hydrogen bonds used to break apart molecules like $\mathrm{NaCl}$. That is, the power to form hydrogen bonds is a higher level property of water molecules.

Moreover, isolated oxygen or hydrogen atoms do not have the power to form hydrogen bonds. It is also not a simple additive power, unlike the power of two individual ten pound bricks to push a scale's pointer to a twenty pound mark, a power lacked by the individual bricks but nonetheless available to the combined bricks irrespective of their arrangement (aside from being on the scale). Instead, the oxygen and hydrogen atoms must be covalently bonded, resulting in a

\footnotetext{
${ }^{24}$ In a footnote discussing water dissolving salt, Marmodoro also claims that water and salt are genuine macro substances that have powers, but also states she is unable to give a full defense. In this section, I offer the needed defense by presenting detailed reasons why water and salt molecules are emergent substances with emergent powers. See Marmodoro (2017: 76, fn. 34).

${ }^{25}$ As we saw in section 3.2

${ }^{26}$ See, for example, Stump (2013).
} 
charge redistribution, in order for the power to form hydrogen bonds to emerge. ${ }^{27}$ Two hydrogen atoms and one oxygen atom cannot break $\mathrm{NaCl}$ 's ionic bonds even if they interact with the $\mathrm{NaCl}$ molecule at the same time. The hydrogen and oxygen must be covalently bonded.

Notably, additional support for the assumption that $\mathrm{H}_{2} 0, \mathrm{NaCl}$, and their powers are strongly emergent can be found from the arguments of two important critics of the agent/patient distinction, Mumford and Anjum. They argue that $\mathrm{H}_{2} \mathrm{O}$ 's power is not reducible to its parts' powers because the powers of the whole emerge from the interacting components, and the interacting components themselves are "changed by their causal participation in the whole" (2017: 98). The change of the component parts, according to Mumford and Anjum, explain why the parts' powers are not simply aggregated to confer higher level powers on the whole. Instead, "water, for example, has a power to put out fires, but neither of the components of water can put out fires; indeed, they would fuel them" (2017: 98-9). Additionally, "chlorine is a poisonous gas; sodium ignites spontaneously on water. But sodium chloride has neither of these causal powers. And it tastes salty, which none of its components do" (2017: 98-9). So it is plausible to hold that molecules and macromolecules are not reducible their subatomic parts and it is also plausible to hold that interactions between such molecules are not reducible to interactions between their parts. Instead, they are emergent entities with emergent powers.

\subsection{Objection: Asymmetry is Subjective}

A second objection, which points to another assumption of my account, comes from Ingthorsson's argument against the agent/patient distinction. Ingthorssson argues that while we

\footnotetext{
${ }^{27}$ As both Stump (2013) and Mumford and Anjum (2018) argue, this account of emergence is consistent with physical causal closure, just not basal closure. Instead, it's a variety of top-down causation. For example, when a water molecule moves due to its forming a hydrogen bond with $\mathrm{NaCl}$, the whole water molecule - including its atomic constituents - moves, but the atomic constituents would not move unless the whole molecule moved due to the whole water molecule's hydrogen bond with $\mathrm{NaCl}$.
} 
“often experience interactions as being asymmetrical", the "experience of asymmetry is purely subjective" (2002: 18-19). Take a brick remaining intact after shattering a window. According to Ingthorsson:

It does appear to be more 'fatal' for a window to be smashed to smithereens than for a brick to lose momentum. But, surely, the sense in which the breaking, or destruction of objects in general, is 'fatal', is a subjective evaluation. (2002: 18-19)

Ingthorsson furthermore clarifies that "subjective" means "dependent on our explanatory interests" (2002: 18-19).

In response, I note that Ingthorsson's example of a brick shattering a window involves artifacts. In the case of artifacts, Ingthorsson is perhaps correct that an interaction being "fatal" to one object (e.g., a window) while not fatal to another (e.g,. a brick) is subjective and dependent merely on our explanatory interests.

However, the examples I've used are interactions where entities change their natural kind. If realism about atomic, chemical, and molecular kinds or at least microstructure is true, then it is not merely subjective that interactions between $\mathrm{H}_{2} \mathrm{O}$ and $\mathrm{NaCl}$ molecules are fatal for the $\mathrm{NaCl}$ molecules. ${ }^{28}$ The $\mathrm{H}_{2} \mathrm{O}$ molecules persist while the $\mathrm{NaCl}$ molecules genuinely do not. Instead, they change kind, into $\mathrm{Na}^{+}$and $\mathrm{Cl}^{-}$ions. Likewise for interactions between enzymes and substrates. So if there are natural kinds, specifically chemical and molecular kinds, then there is a fact of the matter when one entity changes in kind while the other when interacting.

Of course, electromagnetic forces' influences are symmetrical. But that is consistent with a different sort of asymmetry that I've argued provides grounds for the agent/patient distinction: an asymmetry of persistence of interacting entities. That one entity persists while another does not in these interactions is a genuine ontological asymmetry. It is not subjective that enzymes

\footnotetext{
${ }^{28}$ I do not defend chemical and molecular kinds in this paper. For classical accounts, see Kripke (1980) and Putnam (1975). For a nuanced take, see Hendry (2015).
} 
persist while substrates do not when interacting. ${ }^{29}$ Therefore, Ingthorsson's argument does not challenge the criteria I've argued are sufficient for the agent/patient distinction.

\subsubsection{The Argument from Functions}

In the case of enzymes and substrates interacting, there is an additional reason to distinguish agents from patients and hence an additional response to Ingthorsson's challenge. According to biologists, when interacting with substrates, the two-fold biological function of enzymes is: (i) to change the substrate's kind, resulting in products the cell needs that differ in kind from what the substrate was prior to interacting with the enzyme; while (ii) the enzyme persists, enabling it to change another substrate. One finds (i) and (ii) in functional attribution statements in biology textbooks:

Enzymes speed up reactions, often by a factor of a million or more, without themselves being changed - that is, they act as catalysts that permit cells to make or break covalent bonds in a controlled way. It is the catalysis of organized sets of chemical reactions by enzymes that creates and maintains the cell, making life possible. (Alberts 159, emphasis added)

The human body is characterized by an extremely complex system of interrelated chemical reactions. All these reactions must occur at carefully controlled rates to maintain life. A large number of marvelously efficient biological catalysts known as enzymes are necessary for many of these reactions to occur at suitable rates. (Brown 608-9, emphasis added)

As Marmodoro has argued, while agency, patiency, activity, and passivity are functional roles, the grounds for the roles are metaphysical (2017: 75). ${ }^{30}$ In this section, I show that Marmodoro's thesis has strong support from a domain that has been given little to no consideration in discussions of the active/passive power distinction: biological functions. Importantly, the

\footnotetext{
${ }^{29}$ As Marmodoro argues, various metaphysical differences between interacting entities can provide grounds for the asymmetry that can ground distinguishing agents from patients. My paper presents two detailed examples of one such important and widespread metaphysical difference. See Marmodoro (2017: 73)

${ }^{30} \mathrm{In}$ the following two sections, I respond in depth to an objection that if agency and patiency are roles, the distinction is subjective.
} 
functional attributions of enzymes are consistent with naturalism, and enzymes have their functions independent of human interest. I note that while philosophers of biology distinguish between two types of functional attributions: causal role attributions and selectionist attributions, most biologists do not explicitly clarify the sort of attribution being made and oftentimes blend both accounts. ${ }^{31}$ Nonetheless, there are plausible reasons to hold that enzymes function as agents, satisfying (i), (ii), or both (i) and (ii) on both causal role and selectionist accounts. I'll start with causal role accounts.

On causal role accounts of function, an entity's function is its contribution to the operation or capacity of the whole system of which it is a part. ${ }^{32}$ The entity's function is the specific causal role within the larger system's operation — how the entity enables the system to behave as it does. The causal role account is then an instrumentalist account: the function of an entity $E$ is its contribution to a capacity $C$ of $E$ 's containing system $S$. E could also make a different contribution to a different capacity $C^{\prime}$ of $S$ or a different system $S$ '. For example, the heart's circulatory system function is to pump blood. The heart also makes thumping noises, which is a side effect with respect to its circulatory system role but is a function helpful for medical diagnosis. As the causal role account of functions is instrumentalist, relative to some capacities, an entity might play the agent role. With respect to other capacities, the same entity plays the patient role. This does not challenge my account, as my account holds that agency and patiency are roles that entities play in some types of interactions.

With respect to role (i), enzymes change substrate molecules' kind, resulting in products the cell or body needs. Take digestive enzymes: The digestive system's capacity is to break down food into its chemical constituents without breaking down the organism itself (i.e., without

\footnotetext{
${ }^{31}$ For a general overview of biological functions, see Godfrey-Smith (2014) and Okasha (2019).

${ }^{32}$ For a recent defense of causal role accounts of functions, see Cummins and Roth (2010).
} 
digesting one's self). Digestive enzymes contribute to that capacity. With respect to role (ii), enzymes persist in their interactions with substrates and can break down further substrates upon releasing their products. Enzymes contribute to the digestive system's capacity to break down food without exhausting the organisms' resources, as the same enzyme can break down many food molecules while itself persisting.

A selectionist (or aetiological) functional attribution of an entity is equivalent to an explanation of why the entity was selected via natural selection to evolve as it did in the organism or cell. ${ }^{33}$ That is, an entity's function is the effect of the entity favored by natural selection. So a selectionist account of an entity's function explains why the entity is there. With respect to role (i), enzymes are selected because they bring about kind changes in certain substrates. By selected, I mean that organisms and cells with the genes for the enzyme survive and reproduce. For example, organisms with enzymes that break down environmental toxins into harmless products are better fitted to their environment and more likely to be reproductively successful. This also applies to gene expression in differentiated cells: cells express the genes for enzymes in only certain parts of an organism rather than others (e.g., digestive enzymes are expressed by stomach rather than lung cells).

With respect to (ii), it's crucial that enzymes persist when interacting with substrates. If enzymes did not persist, then cells would constantly need to replenish the enzymes to get the products necessary for the cell. While it is possible that macromolecules that interact with substrates also changed kind, needing to be replaced, that would be incredibly inefficient. Cells with genes for macromolecules that persist in interactions with substrates that become products needed by the cell are more likely to persist and successfully reproduce cells with the same

\footnotetext{
${ }^{33}$ For defenses of selectionist (also known as 'aetiological') accounts of functions, see, for example, Godfrey-Smith (1994), Milikan (1984), Neander (1991), and Wright (1973).
} 
genes. So I argue that on both causal role and selectionist accounts of functions, there are principled reasons to hold that when interacting, enzymes are agents and substrates are patients.

\subsection{If Agency and Patiency are Roles then the Distinction is Subjective}

Here I address an objection similar to the one in 4.2, but which merits further consideration. I express the objection thus:

Given that agency and patiency are extrinsic roles that entities play, depending on the types of entities they interact with, the agent/patient distinction is a merely pragmatic or conventional distinction. The agent/patient distinction does not reflect any ontic categories; it is not an ontological distinction.

In response, I argue first that while agency and patiency are roles on my account, they are nonetheless objective and mind-independent roles that entities play, depending on the other entities interacted with. ${ }^{34}$ By objective and mind-independent, I mean that it is not the case that enzymes and water molecules, for example, persist while substrates and salt molecules do not because of the subjective or pragmatic explanatory interests of biologists and chemists. It is a mind-independent fact that when enzymes interact with substrates, enzymes persist while substrates change kind. Likewise, as Marmodoro has pointed out, it is a mind-independent fact that when water and salt molecules interact, water molecules break the salt molecules into $\mathrm{Na}^{+}$ and $\mathrm{Cl}^{-}$ions, while salt molecules do not break up water molecules (Marmodoro 2017: 73).

Second, to press this point further, it's important to clarify the term "role" in claiming that agency and patiency are roles, which has not been done yet. I'll start with what "role" does not mean. Take an actor playing the role of a surgeon performing surgery on a show. The actor, of course, is not really a surgeon and not really conducting surgery. Instead, the actor is

\footnotetext{
${ }^{34}$ In this section, I defend at length a point originally made by Marmodoro, who argues "the grounds for allotting these roles are not epistemological but metaphysical" (2017: 75).
} 
pretending. This is not the notion of a role in my argument that agency and patiency are roles. In interactions where entities play the agent and patient roles, the patient actually changes while the agent actually persists.

Take instead an assistant tasked with driving the actor to the set. Unlike the actor playing the surgeon, when the assistant drives the actor, the assistant is not pretending. We do not label the assistant "the driver" for pragmatic or conventional reasons. The assistant actually drives the actor; the actor is actually driven. This is closer to my account of agency and patiency as roles: the role is a function an entity assumes. Enzymes, as shown in 4.2, function as agents when interacting with substrates. Substrates change kind while enzymes persist, ready to change another substrate into a product.

There is an important difference between the assistant driving the actor and enzyme/substrate and water/salt molecule examples, yet this difference bolsters my account. The actor could just as well drive the assistant. However, when enzymes with certain intrinsic properties interact with substrates with certain intrinsic properties, the substrates cannot break up the enzyme. Likewise, salt molecules cannot break up water molecules. ${ }^{35}$

Third, a reason that agency and patiency not being intrinsic properties does not entail that the distinction is subjective can be shown via two analogies, which until now have not been considered. The first is with relations. Earth is closer to Venus than Mars. Yet Earth's being closer to Venus is not an intrinsic property. That does not entail, however, that it's merely pragmatic or conventional to hold that Earth is closer to Venus than Mars. Likewise, agency and patiency being extrinsic roles rather than intrinsic features does not entail that they are merely pragmatic or conventional labels assigned to interacting entities rather than genuine roles.

\footnotetext{
${ }^{35}$ See also Marmodoro (2017: 73).
} 
I note again an important difference between relations and agency and patiency, but it's a difference that again strengthens my case. Earth's being closer to Venus than Mars is not dependent on the planets' intrinsic properties. However, agency and patiency, while extrinsic roles of interacting entities, are dependent on the entities' intrinsic properties.

The second analogy is more relevant to causation. Take an electron's negative charge, a power. When electrons interact with like-charged particles, the charge is a repulsive power. When electrons interact with oppositely-charged particles, it's an attractive power. So, whether an electron's charge is attractive or repulsive depends on both the intrinsic features of the charge but also the properties of the particles interacted with. Hence, an electron's charge being attractive or repulsive is an extrinsic role. Nonetheless, an electron's charge isn't held to be attractive or repulsive for pragmatic or conventional reasons. Electron's really repel other electrons and really attract protons.

Likewise, while agency and patiency are extrinsic roles, whether entities play those roles is dependent on the intrinsic properties of the interacting entities. So I argue that if it's not pragmatic or conventional to hold that particle charges are sometimes attractive and sometimes repulsive, depending on the charges of particles interacted with, then it's not merely pragmatic or conventional to hold that sometimes entities play agent roles and sometimes they play patient roles, depending on the entities interacted with.

\subsection{The Distinction Adds Nothing to Ontology}

The final objection addressed can be expressed thus: If no entities are intrinsically agents or patients and no powers are intrinsically active or passive, the distinctions add nothing to ontology. ${ }^{36}$ Hence, there's no real substantive debate between my account and critics' accounts.

\footnotetext{
${ }^{36}$ Compare to Aristotle, who in Categories Ch. iv and ix holds that active and passive belong to distinct categories of being. Noted in Hansson-Wahlberg (2019: 7).
} 
This is a new objection — raised by Hansson-Wahlberg — to accounts of the agent/patient distinction that hold that agency and patiency are roles, which has not yet been specifically responded to:

Perhaps something like this view is in fact all that is intended by powers theorists ostensibly postulating active and passive powers. Perhaps they merely wanted to say that ontologically speaking there is only one kind, or category, of power: active causal power, i.e. power to bring about change. In a causal encounter, active causal powers of the objects involved come together in such a way that they cooperate to produce the manifestation effect. Linguistically, and conventionally, we call those active causal powers that happen to be situated in the object that undergoes intrinsic change (or the most intrinsic change) passive powers or liabilities. (2019: 6-7)

As activity and passivity are roles rather than intrinsic features of entities or powers, the view does not, according to Hansson-Wahlberg, "involve a postulation of distinct kinds or categories of power" (2019: 7, fn 11). I've already responded to the objection that if agency and patiency are extrinsic roles, then agency and patiency are merely linguistic or conventional labels. Here, I address the similar objection that if agency and patiency are roles, there is - in the end — no difference between my account and the distinction's critics' accounts.

In response, I note first that many targets of my account are critics' claims (as shown in Part 2) that the agent/patient distinction is "unhelpful" (Martin 1993: 182), "purely subjective" (Ingthorsson 2003: 4), or that it has no "principled basis" (Mumford and Anjum 2018: 269). Even though I agree that agency and patiency are not intrinsic features of entities but rather extrinsic roles, I have nonetheless argued that there are objective and principled reasons to distinguish agents from patients in many interactions.

Second, as already argued, while agency and patiency are not intrinsic features of entities, the intrinsic properties of interacting entities determine whether they are agents or patients in interactions. So, metaphysics grounds the agent/patient distinction. Aristotle and Aquinas similarly held that most entities can be both agents and patients, depending on what they interact 
with. ${ }^{37}$ The only pure agent is God/the unmoved mover and the only pure patient is prime matter.

Third, some of our best physical theories support the distinction. Recall, for example, that the agent/patient distinction is laden in the notion of catalysis: catalysts are entities that cause reactions without themselves being consumed by the reactions. If metaphysics should be rooted in our best physical theories and our best theories posit catalysts, then there is ontological support for the agent/patient distinction. Enzyme function provides similar support: a function of enzymes is to persist while changing substrates into products. Of course, a devout reductionist who believes that only physics should inform our ontology would reject deriving metaphysical theses from chemistry and molecular biology, the domains where catalysts and the enzyme functions are found. However, in 4.1, I presented reasons to reject such a reductionist ontology, a rejection shared by important critics of the agent/patient distinction.

\section{Conclusion}

In this paper, I argued that there is a principled basis for distinguishing agents from patients in many interactions. Support stems from a widespread type of causal interaction, resulting in a type of ontological asymmetry that provides principled grounds for distinguishing agents from patients. The type of interaction where the asymmetry is found is when one of the entities changes in kind, structure, powers, or intrinsic properties while the other does not. Interactions of this type are abundant in chemistry and molecular biology. Examples include the actions of enzymes on substrates and $\mathrm{H}_{2} \mathrm{O}$ molecules breaking the bonds of polarized molecules. I then articulated and to a limited extend defended several commitments of my account: emergent chemical and molecular entities and powers, chemical and molecular kinds, and that the

\footnotetext{
${ }^{37}$ See, for example, Aristotle, Physics 202a5-12.
} 
agent/patient distinction is laden in functional attributions of enzymes. If these assumptions are plausible, then it is also plausible to distinguish agents from patients in many interactions.

Lastly, I responded to several variants of an objection that given that agency and patiency are roles, the distinction is subjective.

\section{Works Cited}

Alberts, Bruce, Alexander Johnson, Julian Lewis, Martin Raff, Keith Roberts, and Peter Walter. 2008. Molecular Biology of the Cell. 5th Ed., New York: Garland Science.

Aquinas, Thomas. 1981. Summa Theologica. Translated by The Fathers of the English Dominican Province. Westminster: Christian Classics. Abbreviated as ST. Cited by Book, Question, and Article.

Aristotle. 1984. The Complete Works of Aristotle. 2 Volumes. Edited by Jonathan Barnes. Princeton: Princeton University Press. Cited by Book, Chapter, and Becker Number.

Bogaard, Paul A. 1978. "The Limitations of Physics as a Chemical Reducing Agent", Proceedings of the Philosophy of Science Association 2: 345-56.

Brown, Theodore., H. May, Bruce Bursten, and Catherine Murphy. 2009. Chemistry: The Central Science. $11^{\text {th }}$ Ed., Upper Saddle River: Pearson.

Bunge, M. (1959/2009). Causality and modern science, 4th edition. New Brunswick: Transaction Publishers.

Cummins, Robert and Martin Roth. 2010. "Traits have not evolved the to function the way they do because of a past advantage." In Francisco J. Ayala and Robert Arp (eds) Contemporary Debates in Philosophy of Biology. Malden: Wiley-Blackwell, 72-86.

Godfrey-Smith, Peter. 1994. "A modern history theory of functions.” Nous 28: 344-62. . 2014. Philosophy of Biology. Princeton: Princeton University Press.

Harré, R.M. 1970. "Powers.” British Journal for the Philosophy of Science 21: 81-101.

Heil, John. 2012. The Universe As We Find It. New York: Oxford University Press.

Hendry, R.F. 2015. “Are Chemical Kinds Natural Kinds?” In Uskali Mäki, Ioannis Votsis, Stéphanie Ruphy, and Gerhard Schurz (eds), Recent Developments in the Philosophy of Science: EPSA13 Helsinki. Cham: Springer International Publishing, 251-264. 
. 2017. "Prospects for Strong Emergence in Chemistry." In Michele Paolini Paoletti and Francesco Orilia (eds), Philosophical and Scientific Perspectives on Downward Causation. New York: Routledge: 146-163.

Ingthorsson, R.D. 2002. “Causal Production as Interaction.” Metaphysica, 3, 87-119.

Kripke, Saul, 1980. Naming and Necessity, Oxford: Blackwell.

Locke, John. 1690. An Essay Concerning Human Understanding. Edited by Peter Nidditch. Abbreviated as ECHU. Oxford: Oxford University Press. Cited by Book, Chapter, and Section.

Lowe, E. J. 2013. “Substance Causation, Powers, and Human Agency.” In Sophie Gibb, E. J. Lowe, and R. D. Ingthorsson (eds.), Mental Causation and Ontology. Oxford: Oxford University Press, 153-72.

Marmodoro, Anna. 2017. "Aristotelian Powers at Work: Reciprocity without Symmetry in Causation.” In Jonathan D. Jacobs (eds), Causal Powers. Oxford: Oxford University Press, 57-76.

. 2014. Aristotle on Perceiving Objects. Oxford: Oxford University Press.

. 2020. "Powers, Activity and Interaction.” In Anne Sophie Meincke (ed.), Dispositionalism: Perspectives from Metaphysics and the Philosophy of Science. Cham: Springer, 55-66.

Martin, C.B. 1993. "Power for realists.” In Keith Cambell, John Bacon \& Lloyd Reinhardt (eds.), Ontology, Causality, and Mind: Essays on the Philosophy of D. M. Armstrong. Cambridge: Cambridge University Press, 175-786.

Millikan, Ruth. 1984. Language, thought, and other biological categories: New foundations for realism. Cambridge: MIT Press.

Mumford, Stephen and Rani Lill Anjum. 2018. "Powers and Potentiality." In K. Engelhard and M. Quante (eds), Handbook of Potentiality, Dordrecht: Springer, 261-78.

Mumford, Stephen and Rani Lill Anjum. 2017. "Emergence and Demergence." In M. Paoletti and F. Orilia (eds), Philosophical and Scientific Perspectives on Downward Causation, London: Routledge, 92-109.

Neander, Karen. 1991. "Functions as Selected Effects: The Conceptual Analyst's Defense." Philosophy of Science 58: 168-84.

Nicholson, Daniel J. 2019. "Is the cell really a machine?" Journal of Theoretical Biology 477: 108-126. 
Okasha, Samir. 2019. Philosophy of Biology: A Very Short Introduction.” Oxford: Oxford University Press.

Putnam, Hilary. 1990. "Is water necessarily $\mathrm{H}_{2} \mathrm{O}$ ?" in H. Putnam, Realism with a Human Face, Cambridge: Harvard University Press, 54-79.

Reece, Jane., Martha Taylor, Eric Simon, and Jean Dickey. 2011. Campbell Biology: Concepts and Connections, $7^{\text {th }}$ Edition. San Francisco: Pearson.

Scerri, Eric. 1997. "The Periodic Table and the Electron.” American Scientist, 85: 546-553.

Stump, Eleonore. 2013. "Emergence, Causal Powers, and Aristotelianism in Metaphysics." In Ruth Groff and John Greco (eds), Powers and Capacities in Philosophy: The New Aristotelianism. New York: Routledge, 48-68.

Wahlberg, Tobias Hansson. 2019. "Active Powers and Passive Powers - Do Causal Interactions Require Both?” Philosophia 47: 1603-1612.

Wright, Larry. 1973. "Functions.” Philosophical Review 82: 139-68. 